\title{
Duration and Becoming in Bergson's Metaphysics
}

\section{Abstract}

In this paper, we will insist on four points. First, Bergson's philosophy is a metaphysics of duration, based on a lived experience that is called "intuition". Intuition is a direct experience of the reality as such, because, as duration, the real is not separated from us. Second, intuition is the very "method" of philosophy and Bergson draws a clear distinction between philosophy and science. However, science has also an experience of reality. Bergson's metaphysics follows a dual approach of reality based on two perspectives: philosophy and science. Thirdly, metaphysics is the experience of time, but through this experience we are not locked into the world of our subjective consciousness. Four, duration is certainly not simply lived by our consciousness, as a correlate of our subjective intentionality. Such a statement would be a complete misunderstanding of Bergson's philosophy, since duration is also present as becoming, into the material universe. To be more explicit, duration is not simply a psychological human property, it is also a cosmic one.*

\section{Introduction}

In this paper, we will insist on four points. First, Bergson's philosophy is a metaphysics of duration, based on a lived experience that is called "intuition" (Bergson 1946, 32-33). Metaphysics cannot be pure speculation. It means that, contrary to Kant's philosophy, we can have a direct experience of the reality as such (Ding an sich), because we are considered as an active part of it, and not simply hierarchically included in it. The world is also our world, the real is also our lived participation to the reality. As duration, the real is not separated from us, as some kind of first unmoved engine, or some kind of absent divinity.

Second, intuition is the very "method" of philosophy (Bergson 1946, 32; Deleuze 1968), and Bergson draws a clear distinction between philosophy and science. However, science has also an experience of reality. When science is not

Note: Special thanks to Elie During, who revised the manuscript. 
speculating, it moves in the "absolute" of matter (Bergson 1946, 33, 41; Bergson 1922, 201). Bergson's metaphysics (Bergson 1922, 193) follows a dual approach of reality based on two perspectives, coming from philosophy and from science. Unlike all classical metaphysics from Plato to Heidegger, there is no hierarchical privilege attributed to metaphysics on science. ${ }^{1}$

Thirdly, metaphysics is the experience of time, but through this experience we are not locked into the world of our subjective consciousness. We are also element of the material universe in which our body is included. This experience of inclusion is also an ontological one, meaning that our mind is open to another world than the world of consciousness. But this experience of the material world is coming from science, because science is "life looking outward, putting itself outside itself” (Bergson 1922, 170). It cannot be directly described by philosophy.

Four, duration is certainly not simply lived by our consciousness, as some kind of correlate of our subjective intentionality. Such a statement would be a complete misunderstanding of Bergson's philosophy, ${ }^{2}$ since duration is also present as becoming, into the material universe. To be more explicit, duration is not simply a psychological human property, it is also a cosmic one. "Nevertheless, it is along this thread that is transmitted down to the smallest particle of the world in which we live the duration immanent to the whole of the universe" (Bergson 1922, 11).

Therefore, in order to sympathize with it, intuition must "use ideas as conveyance" (Bergson 1946, 48). Intuition is not able to provide alone a metaphysical experience of cosmic duration as becoming. It needs intelligence to do it. Reciprocally, intelligence is not able to read alone by its explanations and theories the intimate nature of the material universe, which will not only consist into a Being, because the Being of the universe is nothing but also the result of a Becoming.

\section{Duration and Space}

In Time and Free Will, Bergson proposes "to isolate consciousness, from the external world" by a "vigorous effort of abstraction” (Bergson 1910, 90). In order to do this, we must recognize the difference between duration and space. Homogeneous space is already an experience by which consciousness fits with the ma-

1 "In doing this we make a clear distinction between metaphysics and science. But at the same time, we attribute an equal value to both" (Bergson, 1946, 42).

2 See Deleuze (1968); Worms (2006); Miquel (2007); Ansell-Pearson (2018). 
terial world. The more consciousness goes outside itself, and the more it will be able to capture external material entities in homogeneous space. However, duration is not space. Adding the present moment to the previous one, as if they were simultaneous entities, is not dealing with these moments, "but with the lasting traces which they seem to have left in space” (Bergson 1910, 79). Thus, any spatial representation of time, can deal with numbers and prediction, but not with the very concept of succession. Events are not collections of units, and they cannot be represented in space.

As a second deeper argument, a series of sensations has nothing to do with a series of physical qualities, like position or velocity in mechanics (Bergson 1910, 32-74). Qualities can be distinguished and put in order, so that if the series is reversed, we will get some reverse order of qualities. However, sensations cannot be distinguished and measured, as we distinguish and measure qualities, since they can precisely not be simultaneously compared, as qualities do. Such a comparison requires space. ${ }^{3}$ One would counter-argue ${ }^{4}$ that it would be possible to put sensations in order by ordinal measurement, even if we do not compare them. But this order will not be characterized as a functional relation external to its relata understood as variables; like for instance the relation: "A is bigger than B" (Russell 1914) or "C is later than D" (McTaggart 1908). A and B sensations would be interpenetrated and organic entities. As a sensation, the previous sound of a melody is always here in my consciousness. It doesn't disappear in the present, even if it was also in the past. Thus, if we come back to our "deeper self” (Bergson 1910, 125), if we find duration in succession with interpenetration of conscious states, it would be by overcoming in our mind the superficial one, that "retain something of the mutual externality which belongs to their objective causes” (Bergson 1910, 125).

\section{Matter and Memory}

In Bergson's second book, the analysis of the lived duration must be deepened, by completing the scheme of succession with the image of the cone of memory, a first decisive philosophical invention. The lived memory that in fact inhabits our consciousness also shelters a past that is co-extensive (Bergson 1947, 195) with our present, in the sense that precisely it does not coexist with it, like two com-

3 See Deppe (2016).

4 See Berthelot (1911). 
mensurable segments of the same line. ${ }^{5}$ Essentially virtual, memory is then that movement by which the past "expands into a present image, thus emerging from obscurity into the light of day" (Bergson 1947, 173). As coextensive, the past is lived in an internal experience, that cannot be reduced to a material one.

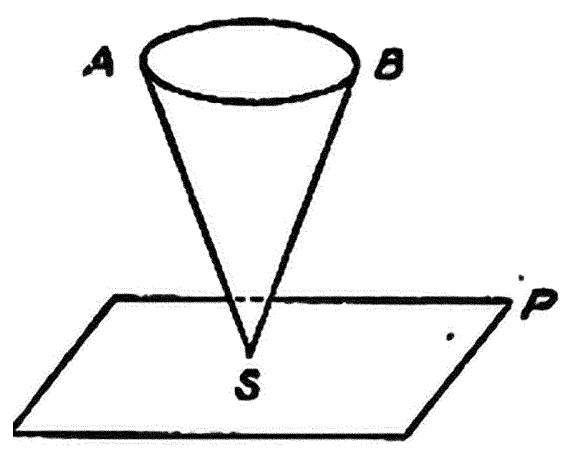

Fig. 1: Bergson's cone of perception in Matter and Memory.

However, the difference between actual and virtual, between the present and the past, is not a difference of substance. First of all, there is a difference of degrees between the present and the past, as habit. Second, there is a difference of nature between the present and the past as souvenir, meaning that the past is not simply an ancient present. The past grows up in the present, as some coextensive internal dimension of it. Finally, the virtual, as a past, can only be characterized recursively from the relationship between the virtual and the actual. The process of consciousness is some kind of creative and virtuous circle. ${ }^{6}$ The virtual is a pure difference; ${ }^{7}$ it is more than the present, but it doesn't exist without the present, as it is clearly mentioned by the image of the cone SAB, which has simultaneously an actual top $S$ in the plane of images $\mathrm{P}$, and a virtual base $\mathrm{AB}$.

As there is no darkness without light, there is no virtual without actuality. The world of our lived consciousness is closed on itself, by placing its double unconscious otherness in it: the past, and the present. The consciousness is closed on the lived co-extensiveness of several layers of the past that are present in the memory as a kind of psychic potential, because it is at the same time open on the present. The opposite of the virtual, the actual is thus also in some way its

5 To be more explicit, the coexistence of two commensurable segments is a property of spatialized time, and the coextension of the past in the present is a property of internal duration. It means of course, that these two words are not synonymous.

6 See Hwang (2019); Hui (2019).

7 See Deleuze (1968). 
contradictory, but it is also its complementary through which the virtual differs unceasingly from itself. ${ }^{8}$ And this is how it finds its consistency. There is therefore no plane of coextension, without the coexistence of contemporary events/ images with my body in the plane P. "At S the image of the body is concentrated; and since it belongs to the plane $\mathrm{P}$, this image does but restore and receive actions emanating from all the images of which this plane is composed" (Bergson 1947, 196).

To sum up, in consciousness duration and memory cannot be lived as our own spiritual world, without to be open to the present, as a pure discrepant dimension of duration. This discrepancy (Miquel 2007) is what characterizes the otherness of the virtual, as a fundamental dimension of the temporality of the human mind. Finally, human consciousness appears as a spiritual entity that “draws from itself more than it has" (Bergson 1946, 38), because of this internal “difference of nature" (Bergson 1947, 71) between the coextensivity of souvenirs and the coexistence of contemporary images in the present.

\section{The Experience of the Universe}

The second important consequence is that, in Matter and Memory, actuality becomes the characteristic of a present, as a dimension of time. ${ }^{9}$ In order to understand this paradoxical point, Bergson introduces three new philosophical statements.

1. Starting from duration, could we ontologically understand what duration is not? The answer is: the negation of consciousness is nothing but matter, as another dimension of duration, the dimension of the present. As my present connected with my body, it means firstly that the present is also a dimension of the human mind. That is why my mind is also material, and not simply spiritual. ${ }^{10}$

2. However, it means also, that my present is not only in my mind. As a material dimension of reality, my present is also included into the material universe.

8 See Miquel (2007).

9 To be more explicit and for people that ignore it, in his first book the French philosopher was dualist. He stated that "within our ego, there is succession without externality; outside the ego, in pure space, mutual externality without succession" (Bergson 1910, 109). On the contrary, in Matter and Memory, externality, as concrete extension is a dimension of duration, the dimension of the present. And reciprocally in Creative Evolution, duration is also present outside of us, as élan vital.

10 To be more explicit, and for people that ignore Bergson's books, it means that in Matter and Memory, the French philosopher rejects explicitly classical dualism. 
And the expanded experience of the presence of my mind, and of my brain into the material universe, is nothing but pure perception. By pure perception, consciousness is open to the pure coexistence of images, which cannot fit with the coextensivity of memory. Objects perceived are not only images. For me, they are not only representations, because I believe immediately, that they exist independently of the way I am thinking of them. I see the table here, and I know by some kind of common sense intuition, that this table exists. Why is it so? Because in my perception, the table, the tree, and finally the garden, are images related to themselves.

As far as the ego is concerned, it does not exist, as such, in my perception. When I perceive, I also perceive my body. And thus, my body is an image in this world of images. But to mean that perception comes from my body and my sense awareness is nothing other than accepting that I perceive material images in the world of images. Through this experience, I do not see the images as correlated with my subjective consciousness. I see, on the contrary, my perception as an image included in another world, to which my consciousness is also open. This is an experience of contemporaneity, through which through which I am going out the immanent world of the duration lived by my consciousness. More precisely, this new experience means that I see the table, the tree and the garden as being linked to the same objective world of images, and that I see these images as also linked to my body, as a subjective center of action and decision. The ideal perception is nothing more than the pure limit between these two perspectives: the world of images in relation to themselves, and the world of images in biological relation to my body and my consciousness.

Finally, to understand the contemporaneity of the material world, I must let both perspectives emerge in my mind. I cannot remain a prisoner of a subjective point of view, since by my perception I see things “in themselves" (Bergson 1947, 59). Such an assertion comes from the fact that contemporaneity, as the coexistence of material images, is another dimension of duration, already present in my mind: the dimension of the present. There is no duration without actuality, and therefore I have no experience of duration lived by my consciousness without at the same time experiencing what is outside my consciousness and uncorrelated with it, ${ }^{11}$ namely the experience of my body, and then that of the relationship between my body and the other bodies of the universe. This enlarged experience shows the locality of our temporal consciousness in the whole universe.

3. The third crucial statement is that prolongation of pure perception is nothing but science, as already explained by Bergson in Matter and Memory:

11 See also During 2018, 422. 


\begin{abstract}
Now no philosophical doctrine denies that the same images can enter at the same time into two distinct systems, one belonging to science, wherein each image, related only to itself, possesses an absolute value; and the other, the world of consciousness, wherein all the images depend on a central image, our body, the variations of which they follow. The question raised between realism and idealism then becomes quite clear: what are the relations which these two systems of images maintain with each other? And it is easy to see that subjective idealism consists in deriving the first system from the second, materialistic realism in deriving the second from the first (Bergson 1947, 13-14).
\end{abstract}

Science gives a true and more developed experience of contemporaneity, because $a$ point of view of the universe as a system of images emerges in scientific explanation, by experiences, measurement and laws. There is no scientific explanation without that our mind would refer to something external to it, without that it could be open to another perspective than the perspective of our mind. In this system of images, every change is correlated with another material change. It is not immediately correlated with a subjective change from the point of view of my consciousness. On the contrary, from the point of view of science, my consciousness appears in its solidarity with my brain, with my nervous system that are parts of the material universe (Bergson 1947, 9; 31; 52). Thus, the coexistence of images has a metaphysical meaning. It is not nothing. The coexistence of material images is not the suppression of reality, it is not a deficient cause. The coexistence of images is the substitution of a dimension of reality by another.

In this new experience of reality, what changes depends on invariant principles, as in any classical physical theory, and truth comes from intelligence, geometric proof, experimental tools. Truth comes from the crystallization of the present in mathematical space. According to Bergson, an experience of contemporaneity of this kind emerges in every scientific theory. Such an experience is not simply a subjective representation of the material universe. Rather, it comes from the intuition that we are included in the material universe as a set of images that exists as such. Consequently, the fact that every scientific theory refers to something takes the form of an ontological commitment by which consciousness is able to go beyond itself. This is why science is thinking and touching the reality, unlike in Heidegger's phenomenological ontology (Heidegger 2001). Science has an absolute view of matter, it has an experience of what it is as such, and not simply of its manifestations (Bergson 1946, 45; Bergson $1922,191)$. Science is also able to stay in touch with the materiality of our perceptions, and with the relations between our perceptions and the central nervous system in our brain. 


\section{Duration in the Universe}

1. However, while scientific explanation does focus on the contemporaneity of the material universe, it cannot be reduced to space, symmetries and invariant structures. The way Bergson understands the difference between space and concrete extension, in Matter and Memory, could be compared with the difference between the concept of "Presentational Immediacy" understood as a "continuum" (Whitehead 1929, 69-82) in Whitehead's metaphysics, and the concept of “common world” (Whitehead 1929, 148).

A continuum is a potential, "whereas actuality is incurably atomic" (Whitehead 1929, 61). Therefore, like space is not matter in Bergson's philosophy, Presentational Immediacy is not contemporaneity, in Whitehead's philosophy. Contemporaneity deals with causal independence of actual entities (Whitehead 1929, 61), which means that they cannot coexist simultaneously in the common world, even if every actual entity is also an element in the constitution of other actual entities (Whitehead 1929, 48), thanks to the principle of relativity (Whitehead 1929, 148). They cannot coexist simultaneously, because each actual entity prehends the other ones as a datum, from its own local perspective, that is why there is no global objective prehension of every actual entity, and that is why the universe is nothing but a process, in which God itself is included, as an actual entity (Whitehead 1929, 88). As Whitehead says, "every actual entity, in virtue of its novelty, transcends its universe, God included” (Whitehead 1929, 94).

According to Bergson, space is only the homogeneous crystallization of this contemporaneity by intelligence. Contemporaneity is actuality. But actuality is not pure nothingness, and it is not timeless. If virtuality is otherness, if virtuality is the lived, recursive and creative return of the past into the present, through which the process of consciousness loops upon itself, contemporaneity must be understood as what is other than otherness. This statement has a very important consequence: it is not possible to reduce contemporaneity to identity and invariance. Identity and invariance are the vision of contemporaneity that emerges from classical scientific theories. ${ }^{12}$ But true contemporaneity is coexistence and repetition, because in Bergson's metaphysics, becoming is not a variety of being. Being is much more a variety of becoming. Would it be possible to show by a philosophical analysis of scientific explanation, that true contemporaneity, as coexistence and repetition, is a variety of becoming, and not simply a variety of being?

12 More particularly in classical physical theories, like mechanics; and of course, not in biology of evolution or in paleontology. 
In coexistence first, actuality and invariance deal with continuity, and second continuity gets a physical cosmic dimension that cannot be fully reduced to a formal and a geometrical one. This way of thinking is already based on the analysis of motion in classical mechanics. Every motion is divisible into earlier and earlier sections, but the act of moving cannot be the result of a division. It can be approximated by infinite calculus, but a geometrical line is not able to make any move! This is the true lesson of Zeno paradox. In electromagnetism, there is continuity, without any objects, entity or atom. It is a continuity which is not obeying to the principle of impenetrability of matter, because of the principle of superposition used in wave mechanics. That is why Bergson insists on Faraday and Maxwell, and that is why he substitutes the concept of "concrete extension" (Bergson 1947, 244) to the concept of “extension” (étendue).

Let's insist to a provisional conclusion, before to go further. Materialism and physicalism are not precise, when these philosophical doctrines try to understand matter, as if it could be independent of duration. Focusing on one famous controversy, this is exactly why no possible debate could occur between Einstein and Bergson. Relativity theory is based on strong structural invariants, like every classical physical theory. But in Relativity theory the notion of contemporaneity is much more complex that it seems to be, at first glance ${ }^{13}$ because the remote action is denied. Every action is a local one, thanks to the choice of the speed of light as an invariant principle. Furthermore, as remarkably emphasized by Einstein itself, ${ }^{14}$ the vision of contemporaneity in Relativity theory is certainly not compatible with the vision of contemporaneity in Quantum Mechanics. In Quantum Mechanics, continuity and coexistence are managed by the complex relation between superposition and measurement that introduces the collapse of the wave function.

Finally, the relation between coexistence and continuity stays a very serious problem in science, which is differently declined in each scientific theory. It certainly explains why unlike Einstein, de Broglie (1941) sympathized with Bergson's views.

2. Second, the intimate structure of the present is not simply contemporaneity. It is also repetition, which deals not only with differential calculus, but also

13 See During (2014); During (2018). “Si l'on renonce à la physique des actions à distance pour s'en tenir aux actions locales (par contact), et si la propagation des effets de proche en proche ne peut avoir lieu qu'à vitesse finie, il est clair en effet que toute connexion prend du temps : le principe de localité se prolonge en principe d'action retardée. Mais cela signifie aussi que tout ne peut être connecté à tout. Cette intuition simple débouche sur une transformation sans précédent de la forme du nexus causal” (During 2018, 422).

14 See Einstein, Podolsky and Rosen (1935). 
with statistic and probabilities. Repetition is identity as the coming back of the same, identity as a result of a becoming, and not as the characterization of a being: "to be in the present and in a present which is always beginning again, -this is the fundamental law of matter: herein consists necessity" (Bergson 1947, 279). Repetition is conceived by Bergson as interrupted tension. The more the past is similar to the present, the more this similarity will return, as in some kind of passive and sleeping memory (Bergson 1896, 247). Thus, repetition introduces a tendency into matter. The same future is coming recursively in the present, like when we throw a coin again and again on the table. The more we throw it, and the best the same distribution of probability is checked, up to a maximum. In Creative Evolution, this hypothesis permitted to define entropy as a fundamental law of matter. It also explained why Bergson quoted Boltzmann in his third chapter (Bergson 1922, 258). Following Boltzmann's H theorem, provided that a law of partition could be defined, the expansion of a monoatomic gas in a closed container would be planned, and the maximization of entropy would be nothing but the attractor of the dynamics of this closed system.

This vision of the same future that keeps coming back introduces a break in temporal symmetry: the future will not be as the present was, and we cannot statistically come back from the future to the present, as we went from the present to the future. Following Boltzmann, such a come-back is possible, in conformity with the so-called "ergodic assumption", but it is statistically improbable. Since the law of evolution of a gas relaxation is based on statistics, and not on determined trajectories, it means that the entropic transformation is not reversible. There is an arrow of time in physics, even in the context of statistical mechanics.

3. However, repetition is not creation. Would it be possible to find some creative duration in the material universe? That's precisely the question asked by Bergson in Creative Evolution. Science insists on the contemporaneity as a crucial dimension characterizing the material universe. Science explains contemporaneity with the help of symmetries and invariant structures. But would it be able to explain life on the basis of an ontology that insists preferentially on the dimension of contemporaneity and repetition?

Following Bergson, life is characterized by the concept-image of élan vital. First of all, life concerns all living organisms in the biosphere. It is not limited to one. It concerns all the organisms as an immanent and creative duration present into them, and into their relations. That is why Bergson says that it looks like a consciousness (Bergson 1922, 24; 28 ${ }^{15}$ ). Secondly, life is not just a memory,

15 See also Worms (2006); Miquel (2007). 
it is a force of anticipation, un élan. Life influences the future, as a force capable of surpassing itself. What exactly does this mean? The first property that characterizes life is that its future is always the result of its activity. It cannot be planned from the present. Thus, creative evolution is a transformation that cannot be characterized by an invariant structure, because of this vis a tergo by which the gate of the future is not closed (Bergson 1922, 108-110). Life is an élan and not an attractor, because the dynamic of life crucially depends on how the living agents live. Its meaning can be analyzed retrospectively, but certainly not prospectively. ${ }^{16}$

As a first consequence, evolution is not predictable, because the causes here, "unique in their kind, are part of the effect, have to come into existence with it, and are determined by it, as much as they determine it" (Bergson 1922, 172-173). As a second consequence, evolution produces novelties. Novelties are not simply inventions. They are inventions of possibilities, because the set of possibilities characterizing the activity of life can never be fully described before living agents act: "Evolution is a creation unceasingly renewed, it creates as it goes on, not only forms of life, but the ideas that will enable the intellect to understand it, the terms which will serve to express it” (Bergson 1922, 108). The third consequence is that living organisms are some kind of local vital forces, they cannot be reduced to mechanical structures, meaning that they future is already depending on the way they act. They are organized and adaptive agents and not simply mechanical devices. What they are doing depend on their individual memory and history.

Would such a vision of life be directed against science? On the contrary, it should be noted that such a philosophical image is not far removed from Darwin's hypotheses and proposals in the Origin of species by means of natural selection (Darwin 1859). Unlike neo-Darwinian population geneticists such as Ronald Fisher (Fisher 1930), Darwin did not focus his entire theory on the hypothesis of natural selection, even though he characterized it as "a paramount power". ${ }^{17}$ The explanation of the origin of new species reposes instead on three principles: "descent with modifications", "natural selection" and "divergence of characters". In accordance with the third one, evolution is represented by a diagram (Darwin 1859, Ch. 4) meaning that the more time is passing, the more different species will appear in a cascade of successive pathways. By the way, this diagram is not a tree, since various independent origins are drawn on it. As a direct consequence, the logic of species classification becomes a chronological

16 See Montévil (2019).

17 See Gayon (1992). 
logic, whereby the genus is no longer an abstract category, but simply a common ancestor.

However, and in accordance with the first principle, the space of possible states characterizing the heredity of a biological system is continuously renewed by the principle of variation at each stage of evolution, so that new species may appear again and again. Finally, natural selection is not simply a power of elimination. It is represented as a creative and plastic power of divergence. It should be noted that this point will be at the center of a very famous scientific controversy between Fisher and Wright during the 20th century.

4. As a second crucial point, the élan vital is nothing but a thermodynamic differential force, producing effects "in which it expands and transcends its own being” (Bergson 1922, 52), because it carries within it an entropic power of waste and dissipation, which again means that there is no life without matter (Di Frisco 2016). Life is like "a container" with "cracks" on the side, through which "steam escapes in a jet", like "a reality that 'is making itself', in a reality that 'unmakes itself"," (Bergson 1922, 261). In La nouvelle alliance (1979), Prigogine and Stengers, implicitly refer to this image as a kind of anticipation of the physical and chemical concept of "dissipative structure". In deciphering the philosophical meaning of this image, one understands that life draws more from itself than it has, because what is not life is also a dimension of life. There is no life without entropy, for the organic nature of life comes from entropy.

However, contrary to a simple dissipative structure, life is represented as a creative tendency inventing material systems that expend more and more entropy over time, enabling more and more new vital functions. Contrary to the vegetal, the animal is expending motion, so that a new vital function could emerge: instinct. Unlike the animal, the human being is able to spend thoughts without acting, so that a new vital function could emerge: intelligence. Finally, life is a polarized intensive activity, and as such, it changes permanently, because what is not life is also an internal dimension of life. There is no intensity without entropy, no biological rhythm without habits, no creation without repetition. Life is the overcoming of the organic, through the inorganic understood as an immanent force, and not simply as an external obstacle or accident.

\section{Conclusion}

1. To sum up, metaphysics alone has no experience of the material universe. The ontological experience of the material universe, is nothing other than an ontological commitment coming from perception and from science. Science is intelligence looking outward, it is the expanded experience in our mind of the mate- 
rial universe, as an entity that also exists as such, that has its own perspective, which is not the subjective perspective of consciousness. This is why, to understand the relation between our consciousness and the material world, metaphysics has to "ride" (Bergson 1946, 48) intelligence. However, when riding intelligence, intuition finds in the physical world, that matter is more than space. Matter has a sleepy memory, and matter has also its own tendency; which is extension. Intuition also proposes that the evolution of life cannot be reduced to an entropic thermodynamic transformation, because of this continuous recursive activity of the organic through and by the inorganic. Such a proposition is not a scientific assumption, but it can be helpful, as some kind of heuristic consideration.

In this way of thinking, metaphysics is not an activity against science. It is only focused on the fact that it would never be possible to give a complete theory of the physical world by science. Any scientific theory, even a purely formal one, would always be incomplete, because it refers to another world than the world of consciousness. Scientific explanation would always be based on the use of concepts like continuity and discontinuity, or on the use on principles and methods that cannot be directly justified by science, because of its external ontological commitment. Philosophical investigation would be based on analogies between the immanent world of consciousness, and the immanent duration present in the universe thanks to the help of new scientific theories and hypothesis. Reciprocally, it means also that there is always some kind of negative control of philosophical concepts and philosophical visions by scientific activity. If they cannot be nor directly neither indirectly connected with science, they are simply sterile and speculative.

2. Second, metaphysics is adding to science a very different ontology, compatible but paradoxically also antagonist with science. Following Bergson, science gives us a plan for the coexistence of material images, in the form of a scientific theory. This experience of objectification is therefore not, as such, symbolic and artificial. On the contrary, it gives a vision of the material dimension of reality. Science refers to something, and at such, it involves some kind of ontological commitment (Bergson 1946, 42). A scientific theory has to be in touch with the physical world, by some kind of expanded intuition. However, objectification deals with measurement, with predictions, with falsifiable assumptions, and finally with the search of symmetries and invariants. That is why the ontology of scientific theories will always introduce a bias in explanation: it will always try to explain what is changing, by what does not change.

On the contrary, metaphysics has to privilege a logic of substitution to a logic of exclusion. In Creative Evolution, Bergson develops what he calls "the two orders theory" (Bergson 1922, Ch. 3-4). The negation of spirituality is not nothing. 
It is matter. How would it be possible to think matter as another order, and not as a pure disorder? In the Platonic, and in the Aristotelian logic, the same has a prevalence on the other. Identity has a privilege on difference, and necessity has a privilege on contingency. More particularly, the relation between necessity and contingency is a hierarchical one, since in Aristotle logic, necessity is defined by exclusion of contingency, as what cannot not to be. There is no possible "included middle", ${ }^{18}$ in such a way of thinking. Conversely, in a logic of substitution:

If $\mathrm{A}$, not $\mathrm{A}$ is not nothing.

The other has a prevalence on the same, because the same can be thought as what is other than the other. In this way of thinking, identity must be understood as a variety of otherness. ${ }^{19}$ This heterodox logic of substitution is obviously at stake in Bergson's definition of life, since its organic nature is recursively coming back continuously from the inorganic entropy of matter, drawing a philosophical picture, that could be directly connected today with the concept of "anti-entropy” proposed by Longo and Montévil (2014).

\section{References}

Ansell-Pearson, Keith (2018), Bergson. Thinking beyond human condition, London. Aristote (1974), Métaphysique, Paris.

Bergson, Henri (1910), Time and Free Will. Essay on the Immediate Given of Consciousness, London

Bergson, Henri (1920), Mind-Energy. Lectures and Essays, New York.

Bergson, Henri (1922), Creative Evolution, London.

Bergson, Henri (1946), The Creative Mind, New York.

Bergson, Henri (1947), Matter and Memory, New York.

Berthelot, René (1911), Un Romantisme utilitaire, étude sur le mouvement pragmatiste.2. Le pragmatisme Bergson, Paris, vol. II.

Boutroux, Emile (1905), La contingence des lois de la nature, Paris.

Darwin, Charles (1859), On the origin of species by means of natural selection, London.

18 The principle of excluded middle states at the epistemic level, that for any proposition, either that proposition is true or its negation is true, in other words: $\neg \mathrm{p}=>\mathrm{p}$, and at the ontological level that, if there is A, then not A cannot be.

19 It should be noticed, that such a way of thinking is not proper to Bergson. It comes from French spiritualist tradition : "Il est inintelligible que la permanence absolue suscite le changement. C'est donc le changement qui est le principe ; la permanence n'est qu'un résultat” (Boutroux 1905, 27). 
De Broglie, Louis (1941), "Les conceptions de la physique contemporaine et les idées de Bergson sur le temps et le mouvement”, in: Revue de Métaphysique et de Morale 48 (4), 241- 257.

Deleuze, Gilles (1966), Le Bergsonisme, Paris.

Deleuze, Gilles/Guattari Félix (1980), Mille Plateaux, Paris.

Deppe, Sonja (2016), "The Mind-Dependence of the Relational Structure of Time (or: What Henri Bergson Would Say to B-theorists)”, in: Kriterion - Journal of Philosophy 30 (2), $107-124$.

Di Frisco, James (2015), “Élan vital revisited: Bergson and the thermodynamic paradigm”, in: The southern Journal of Philosophy 53 (1), 54-73.

During, Elie (2014), “Langevin ou le paradoxe introuvable”, in: Revue de Métaphysique et de Morale 84 (4), 513-527.

During, Elie (2018), “Le temps en soi ou la coexistence des choses”, in : Elie During/Emmanuel Aloa (eds.), Choses en soi, métaphysique du réalisme, Paris, 409- 425.

Einstein, Albert/Podolsky, Boris/Rosen, Nathan (1935), “Can Quantum-Mechanical Description of Physical Reality Be Considered Complete?", in: Physical Review 48, 696-702.

Fisher, Ronald (1930), The genetical theory of natural selection, Oxford.

Gayon, Jean (1992), Darwin et l'après Darwin, Paris.

Heidegger, Martin (2001), Sein und Zeit, Tübingen.

Hui, Yuk (2019), Recursivity and Contingency, London.

Hwang Su, Young (2017), "La figure du cercle vertueux comme aspect essentiel de la causalité créatrice. Une lecture critique de Bergson”, in: Dialogue 56 (02), 317-335.

Longo, Giuseppe/Montévil, Maël (2014), Perspectives on organisms, Biological time, Symmetries, Singularities, Berlin.

McTaggart, James Ellis (1908), “The Unreality of Time”, in: Mind 17 (4), 457-474.

Miquel, Paul-Antoine (2007), Bergson ou l'imagination métaphysique, Paris.

Montévil, Maël (2018), "Possibility spaces and the notion of novelty: from music to biology", in: Synthese 196 (11), 4555-4581.

Prigogine, Ilya/Stengers, Isabelle (1979), La nouvelle Alliance, Paris.

Russell, Bertrand (1914), Our Knowledge of the External World as a Field for Scientific Method in Philosophy, London.

Simondon, Gilbert (1995), L'individu et sa genèse physico-biologique, Paris.

Whitehead, Alfred N. (1978), Process and Reality. An Essay in Cosmology, New York.

Worms, Fréderic (2006), Bergson ou les deux sens de la vie, Paris. 
